\title{
Ultraviolet light emission from resonant gold dipole antennas in air illuminated with intense sub-picosecond terahertz transients
}

\author{
Iwaszczuk, Krzysztof; Zalkovskij, Maksim; Strikwerda, Andrew; Jepsen, Peter Uhd
}

Link to article, DOI:

10.1109/IRMMW-THz.2014.6956349

Publication date:

2014

Document Version

Publisher's PDF, also known as Version of record

Link back to DTU Orbit

Citation (APA):

Iwaszczuk, K., Zalkovskij, M., Strikwerda, A., \& Jepsen, P. U. (2014). Ultraviolet light emission from resonant gold dipole antennas in air illuminated with intense sub-picosecond terahertz transients. Abstract from 39th International Conference on Infrared, Millimeter, and Terahertz Waves, Tucson, AZ, United States. https://doi.org/10.1109/IRMMW-THz.2014.6956349

\section{General rights}

Copyright and moral rights for the publications made accessible in the public portal are retained by the authors and/or other copyright owners and it is a condition of accessing publications that users recognise and abide by the legal requirements associated with these rights.

- Users may download and print one copy of any publication from the public portal for the purpose of private study or research.

- You may not further distribute the material or use it for any profit-making activity or commercial gain

- You may freely distribute the URL identifying the publication in the public portal 


\title{
Ultraviolet light emission from resonant gold dipole antennas in air illuminated with intense sub-picosecond terahertz transients
}

\author{
Krzysztof Iwaszczuk, Maksim Zalkovskij, Andrew C. Strikwerda and Peter U. Jepsen \\ DTU Fotonik - Department of Photonics Engineering, Technical University of Denmark, DK-2800 \\ Kongens Lyngby, Denmark
}

Author e-mail address: kiwa@fotonik.dtu.dk web: www.terahertz.dk

\begin{abstract}
We experimentally show that metallic dipole antennas emit ultraviolet radiation when illuminated with ultrashort high-power terahertz pulses due to ultrafast electron field emission from the metal and consecutive ionization and excitation of atmospheric gas molecules.
\end{abstract}

\section{INTRODUCTION}

$\mathrm{T}$ HE development of high power ultrafast terahertz $(\mathrm{THz})$ table-top sources [1] has opened the door to a rapid progress in nonlinear terahertz optics. Nonlinear $\mathrm{THz}$ phenomena have been demonstrated for plasmas, various gases, liquids, and solid-state materials [2]. Especially $\mathrm{THz}$ nonlinear optics of semiconductor materials has been a widely explored area. Effects such as intervalley scattering [3], impact ionization [4], self phase modulation [5] or high harmonic generation [6] have been demonstrated. But so far, according to our knowledge, very little progress has been achieved on understanding the interaction of strong $\mathrm{THz}$ pulses with metals. Here we present one of the first demonstrations of extreme nonlinear interactions between $\mathrm{THz}$ waves and a metallic system.

\section{RESULTS}

Resonant THz-frequency dipole antennas are fabricated on a high resistivity silicon substrate by a standard UV lithography process after full wave 3D numerical simulations of the resonant properties of the antennas. The structure design was optimized to maximize the field enhancement at the resonant frequency. Figure 1(a) shows the result of optimization for a frequency of $0.6 \mathrm{THz}$, while Fig.1(b) shows the spatial distribution of the $\mathrm{THz}$ electric field amplitude at $0.6 \mathrm{THz}$ in the plane of the antenna. The field has a dipole-type spatial distribution and a field enhancement factor over 25 is reached at the tips of the antenna.

We make the surprising observation that the resonant dipole antenna samples emit characteristic UV light when exposed to strong field $\mathrm{THz}$ transients. Single-cycle terahertz transients with frequency spanning from 0.1 to $2.5 \mathrm{THz}$ and peak electric field strength $>300 \mathrm{kV} / \mathrm{cm}$ are obtained by optical rectification in a tilted-wavefront phase-matching configuration. In a separate experiment [7] we have shown that the emission spectrum is composed of a series of spectrally narrow lines situated between $300 \mathrm{~nm}$ and $400 \mathrm{~nm}$, clearly identifying the THz-induced photoluminescence as originating from the second positive band of molecular nitrogen.

Figure 1(c) shows the intensity of the UV light measured by the PMT tube with a $10 \mathrm{~nm}$ wide $340 \mathrm{~nm}$ bandpass filter in a two $\mathrm{THz}$ pulse experiment. When two $\mathrm{THz}$ pulses arrive at the resonant antenna simultaneously, strong and highly nonlinear enhancement of UV emission is clearly visible. As the THz-THz time delay increases, UV emission decreases and oscillates a frequency of $0.59 \mathrm{THz}$, which agrees very well with the designed maximum field enhancement frequency.

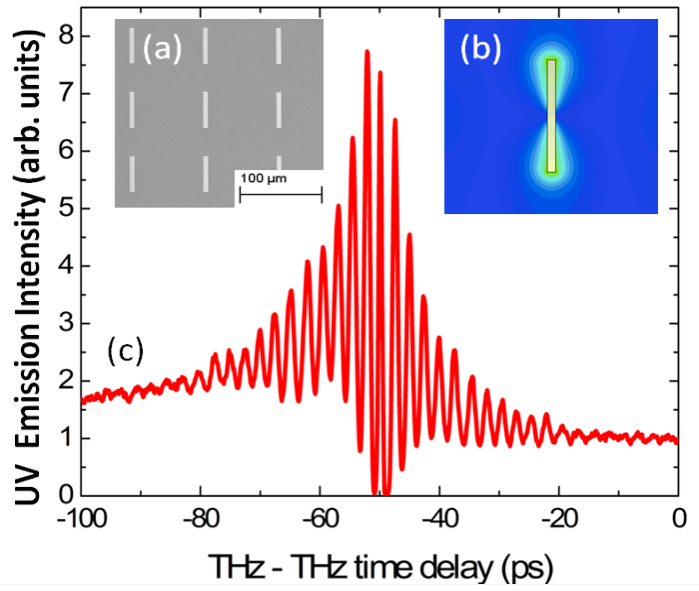

Fig. 1. (a) SEM images of resonant $\mathrm{THz}$ antennas for efficient $\mathrm{UV}$ light emission. (b) 3D simulation of the $\mathrm{THz}$ electric field distribution at the resonant frequency of $0.6 \mathrm{THz}$. (c) UV emission intensity as a function of THz-THz time delay.

\section{SUMMARY}

We attribute observed effect to ultrafast electron field emission from the metal and consecutive ionization and excitation of the gas molecules surrounding the antennas. The resonant metal structure acts as the source of electrons and also provides nearfield enhancement to the terahertz electric. The emitted electrons are subsequently accelerated in the electric field and reach energies as high as $100 \mathrm{eV}$. Such energetic electrons can ionize or excite molecules of the gas surrounding the antenna. During the return to the ground state the molecules can emit photons with energies given by the difference of the energy levels between the excited states and the ground state.

\section{REFERENCES}

[1]. K. Yeh et al. 'Generation of $10 \mu \mathrm{J}$ ultrashort terahertz pulses by optical rectification,' Applied Physics Letters 17, 171121 (2007).

[2]. M. C. Hoffmann and J. A. Fülöp, 'Intense ultrashort terahertz pulses: generation and applications,' Journal of Physics D: Applied Physics 44, 083001 (2011).

[3]. I. Ho and X. Zhang, 'Driving intervalley scattering and impact ionization in InAs with intense terahertz pulses,' Applied Physics Letters 98, 241908 (2011).

[4]. M. Hoffmann et al. 'Impact ionization in InSb probed by terahertz pump - terahertz probe spectroscopy,' Physical Review B 79, 161201 (2009).

[5]. D. Turchinovich et al., Self-phase modulation of a single-cycle terahertz pulse by nonlinear free-carrier response in a semiconductor,' Physical Review B 20, 201304 (2012).

[6]. O. Schubert et al. 'Sub-cycle control of terahertz high-harmonic generation by dynamical Bloch oscillations,' Nature Photonics 8, 119 (2014).

[7]. K. Iwaszczuk, M. Zalkovskij, A. C. Strikwerda and P. U. Jepsen, in preparation 